\title{
Utilização de Saccharomyces cerevisiae como probiótico para tilápias-do-nilo durante o período de reversão sexual submetidas a um desafio sanitário
}

\author{
Fábio Meurer ${ }^{1}$, Carmino Hayashi' ${ }^{2}$, Mateus Matiuzzi da Costa $^{3}$, Valdecir Luiz Mauerwerk ${ }^{4}$, \\ André Freccia 4
}

\footnotetext{
1 Curso de Zootecnia da Fundação Universidade Federal do Vale do São Francisco (UNIVASF) - Av. Presidente Tancredo Neves, 100 , Bairro Centro, CEP: 56306-410, Petrolina - PE.

2 Centro Avançado de Pesquisa Tecnológica do Agronegócio de Pescado Continental, APTA/SAA, São José do Rio Preto - SP

3 Doutorando no Programa de Pós-graduação em Biologia Molecular e Celular da Universidade Federal do Rio Grande do Sul, Porto Alegre - RS.

4 Graduando em Medicina Veterinária e Bolsista de PIBIC.
}

RESUMO - Um experimento foi realizado durante 29 dias com o objetivo de avaliar o uso de Saccharomyces cerevisiae (SC) como probiótico em rações para tilápias-do-nilo (Oreochromis niloticus) durante o período de reversão sexual, submetidas a um desafio sanitário. Foram utilizadas 300 larvas de dois dias de idade $(8,9 \pm 1,02 \mathrm{mg}$ e 0,71 $\pm 0,09 \mathrm{~cm})$, distribuídas em um delineamento completamente casualizado, com dois tratamentos e seis repetições, em 12 aquários de 50 L. O desafio sanitário foi o fornecimento diário de $0,5 \mathrm{~mL}$ de esterco suíno in natura para cada aquário. Os tratamentos constituíram-se de uma ração comercial para a fase de reversão sexual, adicionada (TP) ou não (TT) de $0,1 \%$ de S. cerevisiae. As larvas foram alimentadas, à vontade, cinco vezes ao dia e, ao final do experimento, foram contadas, medidas e pesadas. Dois alevinos de cada tratamento foram escolhidos aleatoriamente para retirada dos intestinos e contagem do número de bactérias e coliformes totais. O desempenho e a sobrevivência não foram influenciados pelo tratamento. A SC colonizou o intestino somente dos alevinos do TP. Não foram observadas diferenças significativas quanto ao número de bactérias e coliformes totais por grama de conteúdo intestinal e da água dos aquários. A utilização de Saccharomyces cerevisiae como probiótico em rações promoveu a colonização do intestino de tilápias-do-nilo durante o período de reversão sexual, mas não influenciou o desempenho e a sobrevivência em um sistema de cultivo com desafio sanitário.

Palavras-chave: alevinagem, larvicultura, nutrição de peixes, Oreochromis niloticus, promotor de crescimento

\section{Saccharomyces cerevisiae as probiotic for Nile Tilapia during the sexual reversion phase under a sanitary challenge}

\begin{abstract}
A 29-d experiment was carried out to evaluate the Saccharomyces cerevisiae (SC) as probiotic in diets for Nile tilapia (Oreochromis niloticus) during the sexual reversion phase, under a sanitary challenge. Three hundred 2-d larvae averaging $8.9 \pm 1.02 \mathrm{mg}$ and $0.71 \pm 0.09 \mathrm{~cm}$ were allotted to a completely randomized design with two treatments and six replicates in twelve $50 \mathrm{~L}$-aquaria. Sanitary challenge consisted of a daily supply of $0.5 \mathrm{~mL}$ of fresh swine manure. Treatments consisted of a commercial diet for the sexual reversion of tilapia, with (TP) or without (TT) $0.1 \%$ of S. cerevisiae. The larvae were fed ad libitum five times a day. At the end of experiment, the fries were counted, measured and weighed. Two fries of each treatment were randomly chosen for gu removal and counting of the number of bacteria and total coliforms. No treatment effect on performance and survival was observed. Only the intestine of TP fries was colonized by SC. No significant differences were observed for bacteria and total coliforms per $\mathrm{g}$ of intestinal content and aquarium water. The use of Saccharomyces cerevisiae as probiotic in diets for Nile tilapia (Oreochromis niloticus) during the sexual reversion period resulted in intestine settling with no effect on performance and survival, in a system of culture with sanitary challenge.
\end{abstract}

Key Words: fingerlings, fish nutrition, fry, growth promoter, Oreochromis niloticus

\section{Introdução}

A tilápia-do-nilo é o segundo peixe de água doce mais cultivado no mundo; sua produção é superada apenas pela das carpas (Alceste \& Jorry, 1998). A produção mundial anual de tilápias ultrapassa 1.300 .000 t e sua criação mantém-se em contínua expansão (Borguetti et al., 2003), com maior concentração no continente asiático (FAO, 2005). Entre as espécies de tilápia, a $O$. niloticus é a mais cultivada no mundo (Lazard \& Rognon, 1997).

A utilização de antibióticos no controle de infecções tem apresentado sucesso limitado na prevenção ou cura de infecções na aqüicultura. O uso expressivo de antibióticos no controle de doenças ou como promotores de 
crescimento aumenta a pressão de seleção sobre os microrganismos, levando naturalmente ao aumento da resistência bacteriana. Além da proliferação das bactérias resistentes, após a morte das não resistentes ao antibiótico, há também a possibilidade de transferência dos genes de resistência a outras bactérias nunca expostas ao antibiótico (Verschuere et al., 2000a).

Diversas alternativas ao uso de antibióticos no controle de doenças têm sido propostas com relativo sucesso na aqüicultura, entre elas, o uso de probióticos (Nikoskelainen et al., 2001; Gram et al., 1999; Gildberg et al., 1997). De acordo com Fuller (1989), os probióticos podem ser definidos como microrganismos vivos suplementados ao alimento que afetam beneficamente o hospedeiro melhorando seu balanço intestinal. Verschuere et al. (2000a) afirmam que os probióticos podem exercer efeito sobre os microrganismos presentes no ambiente aquático e Mattar et al. (2001) acrescentam que os probióticos podem melhorar ou prevenir doenças.

A interação ambiente $\times$ hospedeiro em um ambiente aquático é complexa, pois ambos dividem o mesmo ecossistema. Os microrganismos presentes na água influenciam a microbiota do intestino do hospedeiro e viceversa. Os gêneros presentes no intestino dos hospedeiros parecem ser aqueles microrganismos presentes no ambiente ou no alimento que conseguem sobreviver e multiplicar (Verschuere et al., 2000a).

Vários autores têm demonstrado o efeito de probióticos sobre a diminuição do desenvolvimento de microrganismos patogênicos, geralmente utilizando a inoculação artificial de patógenos específicos (Gildberd et al., 1997; Gram et al., 1999; Verschuere et al., 2000b; Nikoskelainem et al., 2001). Deve-se ressaltar que, em animais mantidos em boas condições de manejo (nutricionais e sanitárias), muitas vezes não são constatados efeitos da inclusão de probióticos sobre seu desempenho (Lima et al., 2003), pois, nessas situações, a possibilidade de contato dos animais com microrganismos patogênicos é menor (Loddi et al., 2000; Zuanon et al., 1998). Nesses casos, pode não haver efeito da inclusão de probióticos nas rações sobre o desempenho animal.

Meurer et al. (2004) não verificaram efeito da adição da Saccharomyces cerevisiae no desempenho de tilápias-donilo durante o período de reversão sexual e atribuíram esse resultado à ausência de microrganismos potencialmente patogênicos no ambiente experimental. Entretanto, LaraFlores et al. (2003) encontraram efeito da S. cerevisiae no desempenho e na sobrevivência de alevinos de tilápia-do-nilo, mas, neste caso, foram aplicados alguns fatores de estresse.

Um dos manejos bastante utilizados na aqüicultura é a utilização da fertilização de viveiros, principalmente nas fases iniciais de cultivo (Palhares et al., 1998). O esterco suíno é um fertilizante usualmente utilizado em propriedades que possuem a suinocultura (Menti et al., 2003). O objetivo com este manejo é baratear a atividade, pois a tilápia-do-nilo é uma espécie que utiliza tanto a dieta artificial quanto a natural ou seu consórcio (Meurer et al., 2003a; Meurer et al., 2002).

Entretanto, o fornecimento de dejetos in natura pode levar à contaminação do ambiente aquático por microrganismos patogênicos (Muratori et al., 2001). Apesar do efeito benéfico do esterco suíno sobre o alimento natural dos viveiros, esta técnica pode se tornar um desafio sanitário aos peixes. De acordo com Abidi (2003), os microrganismos patogênicos são oportunistas e geralmente são encontrados no ambiente aquático natural.

O objetivo neste estudo foi avaliar o efeito da inclusão de Saccharomyces cerevisiae em rações para tilápias-donilo (Oreochromis niloticus) submetidas a um desafio sanitário na fase de reversão sexual sobre os parâmetros de desempenho, sobrevivência e a colonização intestinal.

\section{Material e Métodos}

O experimento foi realizado no período de 12 de março a 11 de abril de 2004 utilizando-se 300 larvas de tilápia-donilo, com dois dias de idade $(8,9 \pm 1,02 \mathrm{mg}$ e 0,71 $\pm 0,09 \mathrm{~cm})$, provenientes da Aquacultura Tupi (Guairá - PR). As larvas foram distribuídas em um delineamento completamente casualizado, com dois tratamentos e seis repetições, em 12 aquários de $50 \mathrm{~L}$, considerando-se a unidade experimental um aquário de 50 L com 25 larvas.

Os aquários foram equipados com sistema de aeração composto de pedras microporosas ligadas por mangueiras de silicone a mini-compressores de ar. Diariamente, os aquários foram sifonados durante a manhã $(6 \mathrm{~h})$ e a tarde (18 h) para retirada das fezes e dos restos de ração, com a troca de $20 \%$ da água nos primeiros dez dias e $50 \%$ até final do período experimental.

A água utilizada no experimento foi proveniente da rede municipal de abastecimento e a ação do cloro foi neutralizada pela adição de tiossulfato de sódio. A temperatura da água foi aferida diariamente pela manhã e à tarde e o pH, o oxigênio dissolvido e a condutividade elétrica da água foram quantificados semanalmente pela manhã, sempre antes da limpeza dos aquários.

Diariamente, aproximadamente $30 \mathrm{~mL}$ de dejetos (fezes e urina) de suínos in natura foram dissolvidos em $600 \mathrm{~mL}$ de água destilada e adicionados aos aquários na proporção de 10 mL/aquário durante o período da manhã, logo após a 
sifonagem. Em termos práticos, a adição diária de esterco suíno correspondeu a $100 \mathrm{~L}$ para cada $10.000 \mathrm{~m}^{3}$ de água ou a $3.000 \mathrm{~L}$ para cada $10.000 \mathrm{~m}^{3}$ mensalmente. O fornecimento dos dejetos de suínos foi considerado desafio sanitário. $\mathrm{O}$ esterco suíno, proveniente de um lote de suínos em terminação de uma propriedade rural no Município de Toledo PR, era coletado e estocado em geladeira e utilizado por uma semana. As sobras eram descartadas e novamente o esterco era coletado e armazenado.

Para confirmação do desafio sanitário imposto, a água utilizada nos aquários experimentais, depois de contaminada pelas fezes suínas, foi analisada semanalmente quanto ao número de bactérias e coliformes totais antes da limpeza matinal. Os dejetos dos suínos também foram analisados quanto ao número de coliformes totais após sua coleta na propriedade.

Utilizou-se uma ração comercial fabricada pela Piscicultura Piracema (Maringá-PR), composta de 38,6\% de proteína digestível (PD), $3.800 \mathrm{kcal}$ de energia digestível (ED)/kg de ração e $60 \mathrm{mg} / \mathrm{kg}$ de ração de 17- $\alpha$-metil-testosterona, formulada de acordo com as exigências preconizadas por Hayashi et al. (2002). No cálculo das rações, foram utilizados os valores de nutrientes digestíveis dos alimentos determinados por Boscolo et al. (2004), Meurer et al. (2003a) e Boscolo et al. (2002). O fornecimento de ração foi à vontade, na forma farelada (Meurer et al., 2003b), em uma freqüência de cinco vezes ao dia, às 7, 10, 13, 16 e 19h, conforme preconizado por Sanches \& Hayashi, 2001.

Foram testados dois tratamentos, um testemunha (TT) e um com probiótico (TP), adicionado na proporção de $0,1 \mathrm{~g} / 100 \mathrm{~g}$ de ração. O probiótico utilizado foi um produto comercial contendo dez bilhões de células vivas/g de Saccharomyces cerevisiae (cada quilograma de ração do tratamento TP possuía um milhão de células vivas). Os valores do número de leveduras por quilo de produto, bem como de ração, foram analisados por meio de contagem em placa, utilizando-se meio seletivo para leveduras yeast growth cloramphenicol(YGC).

Nas análises microbiológicas, determinou a presença de $S$. cerevisiae, coliformes e bactérias totais. Inicialmente, uma amostra do material a ser analisado foi pesada e diluída em $2 \mathrm{~mL}$ de água destilada estéril em um tubo de ensaio. Posteriormente, o tubo contendo o material para análise foi homogeneizado em vórtex e, do material homogeneizado, foram feitas diluições decimais $\left(10^{-1}, 10^{-2}\right.$ e $\left.10^{-3}\right)$ em tubos com água destilada estéril.

Para a contagem de bactérias totais, foi utilizado o meio em ágar padrão de contagem (PCA) em placas de Petri utilizando-se $1 \mathrm{~mL}$ das soluções de $10^{-1}, 10^{-2}$ e $10^{-3}$ e pura. A contagem de coliformes totais foi feita em meio ágar violeta bile vermelho neutro (VBR), em placas de Petri, utilizando-se $1 \mathrm{~mL}$ das soluções de $10^{-1}, 10^{-2}$ e $10^{-3}$ e puro. A presença e a contagem daS. cerevisiaeforam determinadas utilizando-se o meio seletivo yeast growth cloramphenicol (YGC), em placas de Petri, com $1 \mathrm{~mL}$ das soluções de $10^{-1}, 10^{-2}$ e $10^{-3}$ e pura. Após o preparo, as placas de Petri foram colocadas em estufa microbiológica para incubação a $27^{\circ} \mathrm{C}$ por 48 horas.

Ao final do período experimental, todos os alevinos de cada unidade experimental foram contados, pesados e me didos individualmente para determinação dos parâmetros de sobrevivência, biomassa, peso final médio, comprimento final médio e fator de condição corporal (obtido pela expressão peso corporal/comprimento corpora ${ }^{3} \times 100$ ).

De cada unidade experimental foram escolhidos aleatoriamente dois alevinos, que foram insensibilizados em água gelada (cerca de $2^{\circ} \mathrm{C}$ ), pesados e abatidos por decapitação. Posteriormente, o intestino foi extraído assepticamente para determinação da presença de $S$. cerevisiae, coliformes e bactérias totais.

Depois de calculados os valores de desempenho e sobrevivência, bem como os parâmetros físico-químicos da água, os resultados foram submetidos à análise de variância e as médias foram comparadas pelo teste Tukey. Os valores de S. cerevisiae, coliformes totais, bactérias totais e gêneros bacterianos dos peixes e da água foram comparados pelo teste de Wilcoxon, por meio do SAEG - Sistema de Análises Estatísticas e Genéticas (UFV, 1997).

\section{Resultados e Discussão}

O resultado médio dos parâmetros físico-químicos da água dos aquários experimentais (temperatura, oxigênio dissolvido, condutividade elétrica e $\mathrm{pH}$ ) foram, respectivamente, de $26,1 \pm 0,7^{\circ} \mathrm{C} ; 4,9 \pm 0,8 \mathrm{mg} / \mathrm{L} ; 105,9 \pm 6,5 \mu \mathrm{Sm} / \mathrm{cm}$; e 7,6 $\pm 0,3$. A temperatura média da água dos aquários não diferiu entre os tratamentos $(\mathrm{P}>0,05)$, porém, na maior parte do período experimental, manteve-se abaixo de $27^{\circ} \mathrm{C}$, temperatura recomendada para o bom desempenho da espécie (Kubitza, 2000). Os valores dos demais parâmetros físicoquímicos da água foram semelhantes entre os tratamentos ( $\mathrm{P}>0,05)$ e permaneceram na faixa ideal para a espécie (Popma \& Phelps, 1998).

A descrição do número médio das unidades formadoras de colônia (UFC) de bactérias e de coliformes totais da água dos aquários experimentais e do intestinos das tilápias-donilo submetidas aos tratamentos com e sem probiótico encontra-se na Tabela 1. Os valores de UFC de bactérias totais no intestino e na água dos aquários não foram influenciados pelos tratamentos $(\mathrm{P}<0,08)$, entretanto, os 
Tabela 1 - Número médio de unidades formadoras de colônia (UFC) de bactérias e coliformes totais na água dos aquários experimentais e no intestino de alevinos de tilápia-do-nilo (Oreochromis niloticus) alimentados com rações com e sem probiótico

Table 1 - Average number of colony formation units (CFU) of bacteria and total coliforms in the water of the experimental aquaria and the intestine of Nile tilapia (Oreochromis niloticus) fries fed diet with and without probiotic

\begin{tabular}{|c|c|c|c|}
\hline $\begin{array}{l}\text { Microrganismo } \\
\text { Microrganism }\end{array}$ & $\mathrm{TP}^{1}$ & $\mathrm{TT}^{2}$ & $\mathrm{CV}(\%)$ \\
\hline Coliformes totais (UFC/mL água) (Total coliforms, $C F U / m L$ ) & $3,05 \times 10^{2} \mathrm{a}$ & $9,93 \times 10^{2} \mathrm{~b}$ & 96,17 \\
\hline Bactérias totais (UFC/mL, água) (Total bacteria, $C F U / m L$ ) & $4,81 \times 10^{4} \mathrm{a}$ & $4,16 \times 10^{4} \mathrm{a}$ & 170,55 \\
\hline Coliformes totais (UFC/g intestino) (Total coliforms, CFU/g of intestine) & $3,33 \mathrm{a}$ & $38,33 b$ & 169,14 \\
\hline Bactérias totais (UFC/g intestino) (Total bacteria, $C F U / g$ of intestine) & $4,5 \times 10^{5} \mathrm{a}$ & $2,4 \times 10^{5} \mathrm{a}$ & 157,73 \\
\hline
\end{tabular}

1 TP tratamento com probiótico (Treatment with probiotic).

2 TT tratamento sem probiótico (Treatment without probiotic).

Médias com diferentes letras na mesma linha diferem pelo teste de Wilcoxon (Means with different letters in a row differ by Wilcoxon test).

valores de UFC de coliformes totais foram significativamente menores $(\mathrm{P}>0,08)$ para os peixes alimentados com ração contendo probiótico.

O número médio de UFC de coliformes totais encontrados no esterco suíno utilizado para o desafio sanitário foi de $8 \times 10^{5}\left( \pm 7,4 \times 10^{2}\right)$. O número de UFC de levedura (S. cerevisiae) no produto e na mistura final da ração confirmou os valores de garantia $\left(10^{10} \mathrm{UFC} / \mathrm{kg}\right.$ probiótico) e a quantidade do produto adicionado à ração $\left(10^{5} \mathrm{UFC} / \mathrm{kg}\right.$ ração). O número de UFC de S. cerevisiae por g de intestino dos alevinos do tratamento TP foi de $1,79 \times 10^{3}( \pm 650)$, enquanto, no tratamento TT, nenhuma UFC de S. cerevisiae foi encontrada.

Conforme descrito na Tabela 2, os resultados médios finais da biomassa, do peso individual, do comprimento individual, do fator de condição e da sobrevivência não diferiram entre os tratamentos $(\mathrm{P}>0,05)$.

O fornecimento diário de esterco suíno foi considerado desafio sanitário em função dos valores de coliformes totais encontrados na água dos aquários experimentais, os quais se mantiveram acima do nível máximo estabelecido pela resolução do CONAMA (Brasil, 1986) para água destinada à aqüicultura. Esse fato corrobora os obtidos por Menti et al. (2003), que afirmam que o esterco suíno pode comprometer o aspecto sanitário da água pela possibilidade da presença de microrganismos patogênicos nas fezes lançadas aos viveiros.

Entretanto, o tratamento com probiótico não promoveu nenhuma melhora no desempenho, mas foi eficiente na diminuição do número de coliformes totais na água e no intestino dos animais.

Os valores de desempenho e sobrevivência obtidos neste experimento estão de acordo com os dados apresentados por Makridis et al. (2000), que não encontraram efeito do fornecimento de duas cepas de bactérias (4:44 e PB52) sobre os parâmetros de desempenho e sobrevivência durante a larvicultura do turbot (Scophthalmus maximus).
Tabela 2 - Valores dos parâmetros mensurados e calculados de tilápias-do-nilo (Oreochromis niloticus) após 29 dias alimentadas com rações contendo ou não probiótico durante a fase de reversão sexual

Table 2 - Values of measured and calculated parameters of Nile tilapia (Oreochromis niloticus) after 29 days of feeding with and without probiotic, during the sexual reverse phase

\begin{tabular}{|c|c|c|c|}
\hline $\begin{array}{l}\text { Parâmetro } \\
\text { Parameter }\end{array}$ & $\mathrm{TP}^{1}$ & $\mathrm{TT}^{2}$ & $\mathrm{CV}(\%)$ \\
\hline $\begin{array}{l}\text { Biomassa }(\mathrm{g}) \\
\text { Biomass }\end{array}$ & 6,69 & 6,79 & 38,28 \\
\hline $\begin{array}{l}\text { Peso final }(\mathrm{g}) \\
\text { Final weight }\end{array}$ & 0,46 & 0,44 & 36,18 \\
\hline Comprimento $(\mathrm{cm})$ & 3,06 & 3,02 & 11,4 \\
\hline $\begin{array}{l}\text { Lenght } \\
\text { Fator de condição corporal } \\
\text { Body condiction factor }\end{array}$ & 1,50 & 1,52 & 4,15 \\
\hline $\begin{array}{l}\text { Sobrevivência (\%) } \\
\text { Survival }\end{array}$ & 60,67 & 62,00 & 25,45 \\
\hline
\end{tabular}

1 TP tratamento com probiótico (Treatment with probiotic).

2 TT tratamento sem probiótico (Treatment without probiotic).

Os valores de desempenho e sobrevivência deste experimento confirmam os apresentados por Meurer et al. (2004) acerca dos efeitos da inclusão de S.cerevisiae em rações para tilápia-do-nilo durante a fase de reversão sexual. Entretanto, diferem dos valores de desempenho e sobrevivência apresentados por Lara-Flores et al. (2003), que observaram que a inclusão de Saccharomyces cerevisiae em rações para alevinos de tilápia-do-nilo apresentou efeito positivo no desempenho após nove semanas de cultivo.

Os níveis de sobrevivência neste experimento diferiram dos relatados por alguns autores. Carnevali et al. (2004) encontraram efeito positivo da adição de probióticos (Lactobacilus plantarum e Lactobacilus fructivorans) sobre a sobrevivência de larvas de sea bream (Sparus aurata). Gildberg et al. (1997) demonstraram que a adição de Carnobacterium divergens em rações para larvas de bacalhau-do-atlântico (G. morhua) expostos ao patógeno Vibrio anguillarum resultou em mortalidade signifi- 
cativamente menor que a obtida naquelas que não receberam o probiótico. Gram et al. (1999) também observaram resultados diferentes deste experimento quanto à sobrevivência de juvenis de truta arco-íris, pois a utilização do probiótico Pseudomonas fluorescens AH2 aumentou a sobrevivência destes peixes quando submetidos à infecção com Vibrio anguillarum.

Os valores de colonização do intestino pelo probiótico obtidos neste estudo estão de acordo com os relatos de Carnevali et al. (2004), que verificaram a colonização do intestino de larvas de sea breampor meio do fornecimento de L. fructivorans e L. plantarum. Costa et al. (2004) também demonstraram que a inclusão de $S$. cerevisiae proporcionou a colonização do intestino da tilápia-do-nilo durante a fase de reversão sexual. Os valores deste experimento corroboram também os determinados por Gildberg et al. (1997) para a colonização do intestino do bacalhau do Atlântico por Clostridiumdivergens, o que está de acordo com a afirmação de Andlid et al. (1995) de que algumas cepas de levedura podem colonizar o intestino do turbot e da truta arco-íris em número superiores a $4 \times 10^{4}$ UFC sem alterar o desempenho.

O efeito da adição do probiótico sobre o número de UFC de bactérias e coliformes totais apresentados neste experimento está de acordo com os obtidos por Costa et al. (2004), que não verificaram efeito significativo da inclusão da $S$. cerevisiae sobre o número de UFC de bactérias totais no intestino da tilápia-do-nilo durante a fase de reversão sexual. Os resultados neste experimento foram semelhantes aos relatos de Carnevali et al. (2004) de que, durante os primeiros 35 dias de cultivo de larvas de sea bream, não houve efeito da inclusão de Lactobacillus sp. sobre o número de bactérias intestinais.

Comparando os valores numéricos de desempenho e sobrevivência deste experimento aos apresentados por Meurer et al. (2004), nota-se claramente a inferioridade dos valores deste experimento, o que pode ser explicado por alguns fatores ligados principalmente à qualidade da água utilizada, como a temperatura, os microrganismos presentes e os resíduos nitrogenados.

Quando se compararam os valores de temperatura média da água dos aquários experimentais, nota-se os deste experimento foram inferiores aos descritos por Meurer et al. (2004), o que, invariavelmente, diminui o crescimento das larvas, pois ocorre diminuição da ingestão de alimento. O número de microrganismos na água dos aquários foi muito superior neste experimento. Esse aumento, principalmente dos microrganismos patogênicos, pode influenciar negativamente o desempenho, verificando-se a necessidade de maior gasto de energia com a manutenção do sistema imune mais ativo.
Neste experimento, o fornecimento de esterco pode ter ocasionado uma intoxicação crônica por amônia, pois, de acordo com Palhares et al. (1998), o fornecimento de esterco suíno em tanques de piscicultura ocasiona aumento dos resíduos nitrogenados. Destes resíduos nitrogenados, a amônia, dependendo do seu nível, pode ser tóxica, levando os peixes à morte ou a baixo desempenho (Kubitza, 2000). Nos aquários experimentais, a amônia fornecida diariamente (proveniente do esterco suíno) influenciou diretamente o desempenho dos peixes, ao contrário de viveiros, nos quais boa parte desta amônia é absorvida e utilizada pelo fitoplâncton como nutriente (Meurer, 2002).

Na tilapicultura, o período de reversão sexual é de cerca de um mês. Lara-Flores et al. (2003) obtiveram efeito significativo da adição do probiótico ( $S$. cerevisiae) sobre o desempenho de alevinos de tilápia-do-nilo após um período experimental de nove semanas. Carnevali et al. (2004) também verificaram que não houve efeito do probiótico (Lactobacillus sp.) durante os primeiros 35 dias da larvicultura, mas houve efeito significativo sobre o desempenho dos peixesdepois do segundo mês.

\section{Conclusões}

A utilização de Saccharomyces cerevisiae como probiótico em rações para tilápias-do-nilo (Oreochromis niloticus) durante o período de reversão sexual promoveu a colonização no intestino, porém não teve efeito sobre o desempenho e a sobrevivência em um sistema de cultivo com desafio sanitário.

\section{Literatura Citada}

ABIDI, R. Use of probiotics in larval rearing of new candidate species. Aquaculture Asia, v.8, n.2, p.15-16, 2003.

ALCESTE, C.; JORY, D.E. Análisis de las tendencias actuales en la comercialización de tilapia en los Estados Unidos de Norteamérica y la Unión Europea. In: CONGRESSO SULAMERICANO DE AQUICULTURA, 1., 1998, Recife.Anais... Recife: SIMBRAq, 1998. p.349-364.

ANDLID, T.; VÁZQUEZ-JUÁREZ, R.; GUSTAFSSON, L. Yeast colonizing the intestine of raimbow trout (Salmo gairdneri) and turbot (Scophtalmus maximus). Microbial Ecology, v.30, p.321-334, 1995.

BORGUETTI. N.R.B.; OSTRENSKY, A.; BORGUETTI, J.R. Aqüicultura - Uma visão geral sobre a produção de organismos aquáticos no Brasil e no mundo. Curitiba: Grupo Integrado de Aqüicultura e Estudos Ambientais, 2003. 129p.

BOSCOLO, W.R.; HAYASHI, C.; MEURER, F. Digestibilidade aparente da energia e proteína das farinhas de resíduo da filetagem da tilápia do Nilo (Oreochromis niloticus), da corvina (Plagioscion squamosissimus) e farinha integral do camarão canela (Macrobrachium amazonicum) para a tilápia do Nilo. Revista Brasileira de Zootecnia, v.33, n.1, p.8-13, 2004. BOSCOLO, W.R.; HAYASHI, C.; MEURER, F. Digestibilidade aparente da energia e nutrientes de alimentos convencionais 
e alternativos para a tilápia do Nilo (Oreochromis niloticus, L.). Revista Brasileira de Zootecnia, v.13, n.2, p.539545, 2002.

BRASIL. Conselho Nacional do Meio Ambiente - CONAMA. Resolução n.20, de 30 de julho de 1986. Diário Oficial da União. Brasília, julho de 1986.

CARNEVALI, O.; ZAMPONI, M.C.; SULPIZIO, R. et al. Administration of probiotic strain to improve sea bream wellness during development. Aquaculture International, v.12, p.377-386, 2004.

COSTA, M.M.; MEURER, F.; HAYASHI, C. et al. Microflora intestinal de tilápia do Nilo (Oreochromis niloticus) alimentadas com ração contendo probiótico (Saccharomyces cerevisiae). In: REUNIÃO ANUAL DA SOCIEDADE BRASILEIRA DE ZootecniA, 41., 2004, Campo Grande. Anais... Campo Grande: Sociedade Brasileira de Zootecnia, 2004 (CR-ROM).

FAO. Aquaculture production: quantities 1950-2002. Disponível em: <http://fao.org. Acesso em: 14/022005.

FULLER, R. A review: probiotic in man and animals. Journal Applied Environmental Microbiology, v.63, p.1034-1039, 1989

GILDBERG, A.; MIKKELSEN, H.; SANDAKER, E. et al. Probiotic effect of latic acid bacteria in the feed on growth and survival of fry of bacalhau do atlântico (Gadus morhua). Hydrobiologia, v.352, p.279-285, 1997.

GRAM, L.; MELCHIORSEN, J.; SPANGGARD, B. et al. Inhibition of Vibrio anguillarum by Pseudomonas flurescens AH2, a possible probiotic treatment of fish. Applied and Environmental Microbiology, v.65, n.3, p.969-9732, 1999.

HAYASHI, C.; BOSCOLO, W.R.; SOARES, C.M. et al. Exigência de proteína digestível para larvas de tilápia do Nilo (Oreochromis niloticus), durante a reversão sexual. Revista Brasileira de Zootecnia, v.31, n.2, p.823-828, 2002.

KUBITZA, F. Tilápia - tecnologia e planejamento na produção comercial. Jundiaí: Divisão de Biblioteca e Documentação, 2000. 289 p.

LARA-FLORES, M.; OLVEA-NOVOA, M.A.; GUZMANMENDEZ, B.E. et al. Use of bactéria Streptococcus faecium and Lactobacillus acidophilus, and the yeast Saccharomyces cerevisiae as growth promoters in Nile tilapia (Oreochromis niloticus). Aquaculture, v.216, n.1-4, p.193-201, 2003.

LAZARD, J; ROGNON, X. Genetic diversity of tilapia and aquaculture development in Côte D'Ivoire and Niger. Bamidgeh, v.49, p.2, p.90-98. 1997.

LIMA, A.C.F.; PIZAURO JR., J.M.; MACARI, M. et al. Efeito do uso de probiótico sobre o desempenho e atividade de enzimas digestivas de frangos de corte. Revista Brasileira de Zootecnia, v.32, n.1, p.200-207, 2003.

LODDI, M.M.; GONZALES, E.; TAKITA, T.S. et al. Uso de probiótico sobre o desempenho, o rendimento e a qualidade de carcaça de frangos de corte. Revista Brasileira de Zootecnia, v.29, n.4, p.1124-1131, 2000.

MAKRIDIS, P.; FJELLHEIM, A.J.; SKJERMO, J. et al. Colonization of the gut in first feeding turbot by bacterial strains added to the water or biencapusated in rotifers. Aquaculture International, v.6, p.367-380, 2000.

MATTAR, A.F.; DRONGOWSKI, R.A.; CORAN, A.G. et al. Effect of probiotics on enterocyte bacterial translocation in vitro. Pediatric Surgery Int, v.17, p.265-268, 2001.

MENTI, M.M.; SIGNOR, A.; FRECCIA, A. et al. Investigação de Salmonella em diferentes sistemas de cultivo de tilápia do Nilo (Oreochromis niloticus). In: CONGRESSO BRASILEIRO DE ENGENHARIA DE PESCA, 13., 2003, Porto Seguro. Anais... Porto Seguro: Sociedade Brasileira de Engenharia de Pesca, 2003. p.1104-1109.
MEURER, F.; HAYASHI, C.; BOSCOLO, W.R. Digestibilidade aparente de alguns alimentos protéicos pela tilápia do Nilo (Oreochromis niloticus, L.). Revista Brasileira de Zootecnia, v.32, n.6, p.1801-1809, 2003b.

MEURER, F.; HAYASHI, C.; BOSCOLO, W.R. et al. Lipídeos na alimentação de alevinos revertidos de tilápia do Nilo (Oreochromis niloticus, L.). Revista Brasileira de Zootecnia, v.31, n.2, p.566-573, 2002.

MEURER, F. Produção de tilápias. In: CONGRESSO PARANAENSE DOS ESTUDANTES DE ZOOTECNIA, 23., 2002, Maringá. Anais... Maringá: Universidade Estadual de Maringá, 2002. (CD-ROM).

MEURER, F; HAYASHI, C; BOSCOLO, W.R. Influência do processamento da ração no desempenho e sobrevivência da tilápia do Nilo durante a reversão sexual. Revista Brasileira de Zootecnia, v.32, n.2, p.262-267,2003a.

MEURER, F.; HAYASHI, C.; COSTA, M.M. et al. Uso da Saccharomyces cerevisiae como probiótico para a tilápia do Nilo (Oreochromis niloticus) durante o período de reversão sexual. In: REUNIÃO ANUAL DA SOCIEDADE BRASILEIRA DE ZOOTECNIA, 41., 2004, Campo Grande. Anais... Campo Grande: Sociedade Brasileira de Zootecnia, 2004 (CD-ROM).

MURATORI, M.C.S.; MARTINS, N.E.; PEIXOTO, M.T.D. et al. Mortalidade por "septicemia dos peixes tropicais" em tilápias criadas em consorciação com suínos. Arquivo Brasileiro de Medicina Veterinária e Zootecnia, v.53, n.6, p.658-662, 2001 .

NIKOSKELANEN, S.; SALMINEN, S.; BYLUND, G. et al. Characterization of the properties of human and dairy-derived probiotics for prevention of infectious diseases in fish. Applied and Environmental Microbiology, v.67, n.6, p.2430-2435, 2001.

PALHARES, J.C.P.; LUCAS JR., J.; SIPAÚBA-TAVARES, L.H. Efeito da aplicação de estrume de suínos, fresco e fermentado em biodigestores, na qualidade da água para a aqüicultura. Energia na Aqüicultura, v.13, n.4, p.32-39, 1998.

POPMA, T.J.; PHELPS, R.P. Status report to commercial tilápia producers on monosex fingerling productions techniques. In: SIMPÓSIO SUL AMERICANO DE AQUICULTURA, 1., 1998, Recife. Anais... Florianópolis: Associação Brasileira de Aqüicultura, 1998. p.127.

SANCHES, L.E.F.; HAYASHI, C. Effect of feeding frequency on Nile tilapia, Oreochromis niloticus (L.) fries performance during sex reversal in hapas. Acta Scientiarum, v.23, n.4, p.871876,2001 .

UNIVERSIDADE FEDERAL DE VIÇOSA - UFV.SAEG - Sistema para análises estatísticas e genéticas. Versão 7.1. Viçosa, MG: 1997. 150p. (Manual do usuário).

VERSCHUERE, L.; HEANG, H.; CRIEL, G. et al. Selected bacterial strains protect Artemia spp. from the pathogenic effects of Vibrio proteolyticus CW8T2. Applied and Environmental Microbiology, v.66, n.3, p.1139-1146, 2000b.

VERSCHUERE, L.; ROMBAUT, G.; SORGELOOS, P. et al. Probiotic bacteria as biological control agents in aquaculture. Microbiology and Molecular Biology Reviews, v.64, n.4, p.655-671, 2000a.

ZUANON, J.A.S.; FONSECA, J.B.; ROSTAGNO, H.S. et al. Efeito de promotores de crescimento sobre o desempenho de frangos de corte. Revista Brasileira de Zootecnia, v.27, n.5, p.999-1005, 1998. 